\title{
La recepción de la obra de José María Arguedas. Reflexiones preliminares
}

\author{
Carlos García-Bedoya M. \\ Universidad Nacional Mayor de San Marcos \\ carlos.garcia-bedoya@hotmail.com
}



\begin{abstract}
Resumen
José María Arguedas es no sólo un autor clave del canon literario peruano, sino también una figura emblemática de la cultura nacional. El marco simbólico de la conmemoración de los cien años de su nacimiento resulta sin duda oportuno para intentar reflexionar sobre la recepción de su obra. Los estudios de la recepción ofrecen, por cierto, un amplio abanico de posibilidades. Centraré mis reflexiones de manera muy sintética en sólo tres aspectos: la trayectoria de la crítica arguedista, la relevancia teórica de la obra de Arguedas, y la dimensión social y simbólica de su figura.
\end{abstract}

Palabras claves: José María Arguedas, literatura peruana, recepción crítica, indigenismo.

\begin{abstract}
José María Arguedas is not only a key author of the peruvian literature canon, but also an emblematic figure of the peruvien culture. The simbolic framework of the commemoration of the centenary of his birth is without doubt appropiate to try to think about the reception of his work. Reception studies offer certainly a wide range of possibilities. This paper presents three aspects: the critical works about Arguedas, the theorical importance of his works and his social dimension and symbolic relevance.

Keywords: José María Arguedas, Peruvien literature, Reception studies Indigenism.
\end{abstract}


1. Los estudios de la recepción ofrecen un amplio abanico de posibilidades. Cabe en primer lugar examinar la fortuna editorial de la obra: ediciones, tirajes, traducciones. Aunque en la literatura peruana en general, y en el caso de Arguedas en particular, faltan estos necesarios estudios cuantitativos, resulta evidente que la obra novelística de nuestro autor ha gozado de amplia difusión, en particular después de su trágica muerte en 1969. Señalo a los interesados una primera línea de investigación pendiente.

Una segunda posibilidad es examinar la recepción crítica contemporánea, es decir la reacción de la crítica periodística a la publicación de las obras de Arguedas. Esta es también una tarea en lo fundamental pendiente.

Es importante en tercer lugar estudiar la recepción de los escritores. Bastará recordar por un lado las reflexiones juveniles de Vargas Llosa, que tanto contribuyeron a valorar la obra de Arguedas, ${ }^{1}$ para él momento clave de ruptura en el Perú con la que calificaba como "novela primitiva" (la novela indigenista en particular en el caso andino), y por ende antecedente inmediato de la "novela de creación" que empezaban a producir los exponentes del inminente "Boom". ${ }^{2}$ Recordar también, por otro lado, la tensa polémica con Cortázar, que a pesar de lo planteado por Vargas Llosa, seguía ubicando a Arguedas como fiel exponente de esa "novela primitiva" que recusaba. Y por cierto conviene no olvidar el diálogo implícito que entabla el propio Arguedas con diversos escritores contemporáneos en las páginas póstumas de El zorro de arriba y el zorro de abajo.

Una cuarta faceta es la que corresponde a la recepción de la crítica académica o especializada. De nuestros escritores, es sin duda Arguedas uno de los que ha motivado una mayor producción de la crítica, tanto peruana como peruanista. Al lado de César Vallejo y del Inca Garcilaso, es uno de los pocos autores peruanos sobre los que existe una amplia y consistente bibliografía. Se podría añadir Vargas Llosa, aunque en su caso, si bien es mucho lo publicado, quizá, salvo pocas excepciones, esa vasta producción no está al nivel que merece la importante obra vargasllosiana.

Para el caso de Arguedas, se cuenta con un importante acervo crítico, tanto en términos cuantitativos como cualitativos. Por ello mismo se hace sentir la necesidad de una guía que cumpla una función orientadora equivalente a la de la Introducción bibliográfica a César Vallejo de David Sobrevilla. No se intentará aquí ni siquiera un balance preliminar de la crítica arguedista. Me limitaré a señalar que los hitos principales de esa producción se publicaron en los 10 o 15 años posteriores a la muerte del autor. ${ }^{3}$ En ese lapso aparecieron textos fundamen-

1 Ver por ejemplo su artículo de 1964 “José María Arguedas descubre al indio auténtico".

2 Véase su artículo "Novela primitiva y novela de creación en América Latina".

3 Una opinión similar plantea José Alberto Portugal, que ubica el desarrollo de la que él denomi- 
tales como Los universos narrativos de José María Arguedas (1973) de Antonio Cornejo Polar, El mundo mágico de José María Arguedas (1973) de Sara Castro-Klaren, Mito e ideología en la obra de José María Arguedas (1979) de William Rowe, Cultura popular andina y forma novelesca. Zorros y danzantes en la última novela de Arguedas (1981) de Martin Lienhard, a lo que cabe añadir los aportes de Ángel Rama, Julio Ortega, Tomás Escajadillo y Alberto Escobar, entre otros. En las décadas posteriores, la crítica ha brindado aportes parciales, algunos de valía, pero no ha superado el horizonte establecido por la producción de esos años iniciales.

Se hace sentir en la crítica arguedista la necesidad de nuevos enfoques globalizadores que podrían quizá construir un nuevo paradigma alternativo al diseñado por la crítica temprana. Antonio Cornejo Polar era muy consciente de tal urgencia. En una nota de 1994 para la reedición de su libro de 1973, señala que había demorado esa segunda edición porque "cada vez me interesaba más poner de relieve las contradicciones internas que cruzan de parte a parte la obra de Arguedas que la coherencia de su producción narrativa". ${ }^{4}$ En su libro del mismo año 1994, Escribir en el aire, enuncia la aspiración de reexaminar la producción de Arguedas desde la perspectiva de la migración, y en sus últimos artículos diseña la categoría teórica de sujeto migrante. ${ }^{5}$ Quizá en estas reflexiones truncas podemos hallar el germen de un posible cambio de paradigma en la crítica arguedista.

Un caso peculiar y hasta cierto punto marginal en el ámbito académico es el muy difundido libro de Vargas Llosa La utopía arcaica (1996). No cabe aquí discutir este controvertido texto, pues ha motivado amplio debate. Quiero sólo recalcar que Vargas Llosa ve en la obra de Arguedas una utopía antimoderna, pasatista y retrospectiva. No logra pues captar la dimensión prospectiva de la utopía arguediana. ${ }^{6}$ A pesar de la vasta circulación de este volumen, sus planteamientos no han alcanzado amplia aceptación en la comunidad académica especializada.

Me he limitado hasta aquí a señalar algunas posibles líneas de investigación que podrían rendir valiosos frutos. Centraré ahora mis reflexiones en dos aspectos: la relevancia teórica de la obra de Arguedas y la dimensión social y simbólica de su figura.

na "tradición crítica arguedista» en "el periodo que va de finales de los sesenta a finales de los setenta, en el que se forma la base de la fama póstuma de Arguedas”. Véase su libro Las novelas de José María Arguedas, 30.

4 “Nota a la segunda edición” de Los universos narrativos de José María Arguedas, 13.

5 Véanse sus artículos "Condición migrante e intertextualidad multicultural: el caso de Arguedas" y "Una heterogeneidad no dialéctica: sujeto y discurso migrantes en el Perú moderno".

6 En cambio, Portugal resalta esa dimensión prospectiva que "desafía una lectura fundamentalmente realista. Se trataría de la textualización de lo liminal, desde lo cual se expresa no tanto el futuro como lo que aún no es". Las novelas de José María Arguedas, 102. 
2. La obra de Arguedas ha resultado terreno propicio para la reflexión teórica. Esto no solamente en el ámbito de los estudios literarios o ciencia de la literatura, sino también en el de las ciencias sociales. Sería por ello muy oportuno que en este año de su centenario, se culmine por fin la edición de las obras completas de Arguedas, con la publicación de los tomos correspondientes a su vasta obra de reflexión. No sólo cada vez son más valorados los trabajos etnológicos o antropológicos de Arguedas, que evidencian un enfoque de tipo interpretativo o hermenéutico, a contrapelo del positivismo imperante por entonces en esas disciplinas. ${ }^{7}$ Además, los debates actuales en el campo de las ciencias sociales peruanas suelen tener a la obra de Arguedas como un referente ineludible, aunque la deformación profesional de los científicos sociales (al parecer muy convencidos de su omnisciencia) los suele llevar a desdeñar o soslayar los aportes producidos desde los estudios literarios, lo que motiva frecuentes redescubrimientos de la pólvora o lleva a descuidar la especificidad literaria del corpus arguediano. ${ }^{8}$ Es por ello que hasta la actualidad sigue siendo motivo de reflexión el célebre debate sobre Todas las sangres, debate que tanto deprimió a Arguedas; ${ }^{9}$ sin embargo, la historia ha confirmado la hondura y la trascendencia de la visión del mundo andino que él construyó.

Quiero centrarme más bien en el campo de los estudios literarios o ciencia de la literatura, para evidenciar de qué manera, quizá como la de ningún otro autor, la obra de Arguedas ha sido un espacio clave para la reflexión teórica e historiográfica, no sólo en el ámbito peruano, sino en el latinoamericano.

7 Como lo apunta acertadamente Portugal, "el rescate del valor de su obra antropológica fue, en parte significativa, obra de críticos y teóricos de la literatura, en primera instancia”. Las novelas de José María Arguedas, 62.

8 A pesar del tiempo transcurrido, y a pesar de declaraciones bienintencionadas, parecen no ser capaces de aprender la lección: en un reciente libro de homenaje, Arguedas. Poética de la verdad. Segunda mesa redonda sobre Todas las sangres, persisten en esa actitud de excluir el diálogo con los especialistas en el campo literario, olvidando una vez más que la envergadura de Arguedas como héroe cultural descansa principalmente en su prestigio como escritor, lo que haría imprescindible la participación en un diálogo de esa naturaleza de una proporción importante de especialistas en estudios literarios. En cambio, en este volumen de subtítulo aterradoramente irónico, Segunda mesa redonda sobre Todas las sangres, participaron once científicos sociales, por supuesto muy destacados y muy respetables (Julio Cotler, José Matos Mar, Rodrigo Montoya, Edmundo Murrugarra, Hugo Neira, Alejandro Ortiz Rescaniere, Juan Ossio, Carmen María Pinilla, Gonzalo Portocarrero, Aníbal Quijano y Guillermo Rochabrún), un pintor (Fernando de Szyszlo), un estudioso del arte, Ramón Mujica, y sólo un crítico literario, Abelardo Oquendo (por cierto de indudable prestigio, pero no un especialista en la obra de Arguedas). iAl menos en la primera Mesa redonda sobre Todas las sangres eran cuatro contra cuatro! Para tomarlo con un poco de humor, parece que la que ha vivido en vano es la crítica literaria.

9 Para un serio estudio de este debate, véase el reciente libro de uno de nuestros mejores jóvenes arguedistas, Dorian Espezúa, Todas las sangres en debate. Científicos sociales versus críticos literarios. 
Es bien conocido que el concepto de transculturación narrativa, uno de los aportes teóricos más notables del gran crítico uruguayo Ángel Rama, se nutre de modo decisivo de una reflexión sobre la obra de Arguedas. Al retomar el concepto de transculturación, acuñado por el etnólogo cubano Fernando Ortiz, y aplicarlo al estudio de la narrativa latinoamericana, Rama comprende el proceso de modernización de la narrativa latinoamericana, muy visible hacia mediados del siglo XX, desde una óptica mucho más sofisticada que la mera oposición entre una supuesta "novela primitiva" (la del regionalismo) y una supuesta "novela de creación" (la suya propia), tan difundida por los portavoces del "Boom". Rama revela cómo los caminos de la modernización narrativa son mucho más complejos, y no se dan por una mera asimilación de los aportes cosmopolitas de la modernidad internacional, sino también por la vía de la compleja articulación de tales efluvios modernizadores con las culturas regionales de América Latina, dando lugar al florecimiento de esos narradores de la transculturación, de los que destaca a Joao Guimaraes Rosa en el Brasil, a Juan Rulfo en el área mesoamericana, a Augusto Roa Bastos en el cono sur, a Gabriel García Márquez en el Caribe y muy especialmente a José María Arguedas en el área andina. Bastará recordar que, en su fundamental libro Transculturación narrativa en América Latina, después de una primera parte general donde aborda estos procesos de transculturación en la narrativa latinoamericana, centra su atención en la segunda parte en el área andina, tomando como base para esta reflexión la obra antropológica de Arguedas; cabe apuntar que el interés evidenciado por Rama en gran parte de su obra por una disciplina como la antropología, se debe en buena medida a un estudio atento de la obra de Arguedas, tanto en su lado literario como en el etnológico. Finalmente, la tercera parte del libro, que busca ilustrar los procesos de transculturación narrativa a través de un estudio de caso, analiza atentamente Los ríos profundos, quizá la novela canónica de Arguedas por excelencia, a la que concibe como una novela-ópera de los pobres, un tejido de una multiplicidad de voces, revelando así notorias afinidades con los planteamientos de Bajtín.

Por su parte, Antonio Cornejo Polar elaboró las categorías de literaturas heterogéneas, primero, y de heterogeneidad, luego, en gran medida a partir de su constante frecuentación de la obra de Arguedas. Cornejo Polar fue ante todo un gran estudioso de la novela indigenista andina, y vio en ella un primer ejemplo de literatura heterogénea, desgarrada entre dos universos socioculturales. Como es conocido, tales sistematizaciones se nutren de importantes planteamientos de José Carlos Mariátegui. Ampliando luego los alcances de su reflexión, pasa del estudio del fenómeno de las literaturas heterogéneas, primero el indigenismo y luego otras manifestaciones de similares rasgos estructurales, al análisis de la heterogeneidad cultural y social del Perú y de 
América Latina. No voy a abundar en estos aspectos tan conocidos. Sólo cabe añadir que años más tarde, en un esfuerzo de revisión de sus planteamientos en torno a la obra narrativa de Arguedas, propuso la categoría teórica de sujeto migrante, que ubicaba a nueva luz toda la obra arguediana y cuyas potencialidades heurísticas ya visualizaba Cornejo Polar cuando lo sorprendió la muerte. Desde el actual horizonte de los procesos de globalización, en especial en el ámbito cultural, es fácil calibrar la importancia teórica de categorías como las de transculturación, heterogeneidad o sujeto migrante, que ayudan a comprender mejor los procesos de mezcla cultural actuantes en la escena planetaria.

En el ámbito historiográfico, habría que recordar la diferencia establecida por Tomás Escajadillo entre indigenismo "ortodoxo" y neoindigenismo. ${ }^{10}$ En el tránsito del uno al otro, una vez más resulta clave la figura de Arguedas. Escajadillo rastrea la evolución de su narrativa, de una fase inicial apegada a los cánones típicos del indigenismo, representada por Agua o Yawar Fiesta, a una segunda caracterizada por la renovación de los recursos narrativos, representada por novelas como Los ríos profundos o cuentos como "La agonía de Rasu Niti”. Es desde ese balance de la narrativa arguediana que Escajadillo propone la noción de neoidigenismo, que goza de tanta aceptación en nuestra historiografía literaria.

3. El estatuto de Arguedas en la cultura peruana trasciende sin embargo mucho más allá del ámbito académico de los estudios literarios e incluso más allá de su vasto público lector. Arguedas se ha constituido en una figura emblemática para muchísimos peruanos que no han leído su obra o que han apenas frecuentado sus páginas. Algunas frases suyas que ayudan a entender este Perú desgarrado, plural y heterogéneo, han calado hondamente en el imaginario nacional: "todas las sangres", "todas las patrias", frases incorporadas hoy en todo discurso "políticamente correcto". Además, para un vasto sector de peruanos, aquellos identificados con la vertiente andina e indígena de nuestro país plural, es Arguedas auténtica seña de identidad.

La obra intelectual y creativa de Arguedas diseña una utopía con dimensión prospectiva. La definición de utopía sintetizada por Paul Ricoeur ayuda a esclarecer esas implicancias: "La utopía ... es la expresión de todas las potencialidades de un grupo que se encuentran reprimidas por el orden existen-

10 Estas ideas fueron planteadas en su muy influyente tesis doctoral, frecuentemente citada, aunque permaneció inédita en su formato original: La narrativa indigenista: un planteamiento y ocho incisiones (Lima: Universidad Nacional Mayor de San Marcos, 1971). La sección inicial, "Un planteamiento general", que sintetiza su visión global del indigenismo, fue recogida en su libro La narrativa indigenista peruana, 27-102. 
te. La utopía es un ejercicio de la imaginación para pensar un "diferente del ser» de lo social" 11 y añade que "su función es siempre proponer una sociedad alternativa". ${ }^{12}$ Es en tal sentido que la utopía arguediana ha calado hondo en el imaginario de vastos sectores nacionales y hace de este escritor una figura emblemática no sólo de ciertos modos de identidad, de ciertas formas de definirse peruano, sino también de la promesa de otra modernidad, una modernidad propia, no una modernidad copia.

Es quizá en la poesía de Arguedas, ${ }^{13}$ escrita en quechua, donde mejor se evidencia esta opción por una modernidad basada en el diálogo intercultural. Estos poemas no son en modo alguno la celebración de un pasado congelado o el lamento nostálgico de una cultura replegada sobre sí misma. Son cantos que celebran el alumbramiento, al tiempo gozoso y doloroso, de un mundo nuevo.

El poema “Tupac Amaru kamaq taytanchisman (haylli-taki)"es el cantar de gesta de un pueblo que encuentra en la migración una respuesta a los desafíos de la modernidad. Es la enunciación poética de lo que Matos Mar llamó el desborde popular. O también la expresión vívida del discurso de ese sujeto migrante del que nos habló Antonio Cornejo Polar, discurso que asume, sin imposibles armonizaciones, la herencia de la tierra (de la sierra) y la inserción problemática en el nuevo espacio -costeño y urbano- que es, en nuestra peculiar geografía socio-cultural, el espacio por excelencia de la modernidad. Para discursivizar esa gesta, como lo señala Mauro Mamani, retomando planteamientos de Martin Lienhard, se recurre a la andinización de la vanguardia. Así como en la novela El zorro de arriba y el zorro de abajo se aprehendía el hervidero chimbotano, esa harina-mundo, desde categorías andinas, ahora se hace lo propio desde el discurso poético con esta "gesta del migrante", pero recurriendo ya no a la lengua castellana y a un género occidental, la novela, sino a la propia lengua de los runas, el quechua, y a un género de larga tradición en el mundo andino, la poesía, y sus modalidades de raíces ancestrales.

La lectura de otros poemas evidencia cómo Arguedas acepta sin ambages el desafío de la modernidad. Lo hace en su ámbito más emblemático, el de la

11 "L'utopie ... est l'expression de toutes les potentialités d'un groupe qui se trouvent refoulés par l'ordre existant. L'utopie est un exercice de l'imagination pour penser un «autrement qu'être» du social". Cito por su artículo "Lidéologie et l'utopie: deux expressions de l'imaginaire social", incluido en su libro Du texte à l'action. Essais d'herméneutique II, 427. La traducción es mía.

12 "Sa fonction qui est toujours de proposer une société alternative”, Ibid, 428. (Mi traduccción).

13 La bibliografía sobre la poesía de Arguedas es relativamente escasa, en comparación a lo producido sobre su obra narrativa. Los comentarios que siguen se apoyan en buena medida en los análisis de Mauro Mamani en su reciente libro José María Arguedas. Urpi, fieru, qori, sonqoyki. Estudio sobre la poesía de Arguedas, con el que ganó el Copé de Oro en la Segunda Bienal de Ensayo "Premio Copé Internacional 2010". 
técnica. Así en "Jetman haylli", el jet, ese artefacto tecnológico de punta, es apropiado desde categorías del pensamiento andino, evidenciando plasticidad linguiística y cultural.

En su poesía, se enfrenta también Arguedas a otra dimensión clave de la modernidad: el conocimiento, la ciencia, la filosofía, el pensamiento. El caso más conocido es el del célebre poema "Huk doctorkunaman qayay". Este llamado a algunos doctores en modo alguno implica refugiarse en la "diferencia" andina, sino por el contrario, formular una convocatoria, casi un enérgico emplazamiento, al diálogo intercultural. La misma estrategia discursiva puede apreciarse en un poema no incluido en Katatay, ${ }^{14}$ dedicado a otro de esos "doctores dialogantes”, Francisco Miró Quesada Cantuarias.

Incluso en un ámbito distinto, el de la religiosidad, no se refugió Arguedas en una cosmovisión andina supuestamente incontaminada, sino que asumió decididamente el diálogo intelectual con uno de los esfuerzos más serios de renovación del pensamiento católico, la teología de la liberación que elaboró Gustavo Gutiérrez.

En el campo del arte, su actitud es similar. En el poema "Iman Guayasamin" expresa su admiración por el pintor ecuatoriano, que supo combinar en su producción plástica la herencia andina con los más innovadores experimentos formales de la vanguardia. Es ese mismo criterio el que motiva su profunda admiración por César Vallejo, nuestro poeta nacional y universal, cuya obra, nutrida por sus raíces andinas, incursiona en formas de experimentación poética cuya audacia tiene pocos paralelos en la literatura mundial; así cobra todo su sentido la contundente frase de Arguedas en El zorro de arriba y el zorro de abajo: "Vallejo es el principio y el fin". En los diarios incluidos en esa misma novela póstuma, valora desde similar perspectiva la obra de admirados escritores (y amigos). Se trata de algunos de los que Ángel Rama llamará "narradores de la transculturación”: un Juan Rulfo o un Joao Guimaraes Rosa, cuyas obras surgen desde las trastierras mexicanas o desde el sertón brasileño, recurriendo a las técnicas de avanzada de una nueva narrativa latinoamericana (años antes del resonante boom).

14 Entre sus múltiples méritos, el ya citado libro de Mamani tiene el de mostrarnos que, incluso en el caso de un escritor tan prestigioso y tan estudiado como Arguedas, el establecimiento del corpus sigue siendo una tarea pendiente. En efecto, además de los poemas agrupados en el libro póstumo Katatay, la producción poética en quechua de Arguedas incluye un número todavía impreciso y provisional de textos. Y ese corpus parece seguir creciendo: Mauro Mamani tuvo la gentileza de entregarme una fotocopia de un manuscrito de un poema de Arguedas en quechua y castellano, con las respectivas transcripciones e incluso una traducción al inglés. Se trata de un aporte generosamente remitido por nuestro colega Julio Noriega, quizá el mayor especialista en la poesía quechua escrita. 
Igual aspiración modernizadora puede apreciarse en el plano político. Como lo afirmó Arguedas al expresar su admiración por José Carlos Mariátegui, el socialismo no mató en él lo mágico. En los poemas que dedica a Cuba y Vietnam ("Cubapaq" y "Qollanan Vietnam llaqtaman”), ve en las luchas de esos pueblos la posibilidad de una modernidad alternativa, de una modernidad otra. Sin duda lo fascinan también en esas experiencias la eterna lucha de David contra Goliat, con la inesperada victoria del débil, y la esperanza de que también en el caso peruano puedan triunfar los débiles, en especial el indio.

Como hemos visto, no hay pues en Arguedas "nostalgias imperiales", sino una clara apuesta por la modernidad, pero por una modernidad que cancele la pesada herencia colonial, esa persistente colonialidad del poder que ha teorizado Aníbal Quijano. ${ }^{15}$ En todos los terrenos someramente examinados, el de Arguedas constituye temprana expresión de un pensamiento decolonial.

Justamente por las razones reseñadas, Arguedas se ha constituido para múltiples sectores sociales de nuestro país plural en una figura simbólica. Parecía por ello lógico y natural que el año 2011 fuera designado oficialmente como "Año del centenario del nacimiento de José María Arguedas". Como bien sabemos, no ocurrió así. Se prefirió, por razones que bien vale la pena discutir, resaltar en este año el centenario del supuesto "descubrimiento" de Machu Picchu por Hiram Bingham. Como las investigaciones especializadas han demostrado hasta la saciedad que no cabe hablar de tal "descubrimiento", se optó por la especiosa fórmula "Centenario de Machu Picchu para el mundo". En la lógica de una modernización excluyente, lo andino, lo indígena es valorado por su exotismo ante la mirada del sujeto central (europeo o norteamericano), por su rendimiento turístico en el mercado mundial de la "otredad". Quizá también se creyó que, minimizando a Arguedas, se lisonjeaba a Vargas Llosa, con quien se habían producido notorios desencuentros en referencia al Lugar de la Memoria. Sin embargo, nuestro premio Nobel, a pesar de las polémicas opiniones vertidas en su libro La utopía arcaica, se mostró favorable a dedicar el año al centenario de Arguedas.

El ninguneo oficial de Arguedas es la consecuencia de una concepción de la modernidad definida desde los paradigmas del mercado mundial globalizado, una modernidad que excluye no sólo a amplios sectores sociales, sino a componentes centrales de nuestro tejido cultural. Se trata de una mera concepción de la modernidad como copia de las lógicas globalizadoras, en oposición a la modernidad propia que planteara Arguedas, a partir de la articulación de todas nuestras patrias y todas nuestras sangres. Como lo subrayó muy claramente

15 Ver en especial su artículo "Colonialidad del poder, eurocentrismo y América Latina”. 
Ángel Rama, "la modernidad no es renunciable y negarse a ella es suicida; lo es también renunciar a sí mismo para aceptarla". ${ }^{16}$

La decisión de preterir a Arguedas revela la persistencia de lo que Aníbal Quijano ha denominado la colonialidad del poder, esa lógica de exclusión del otro, del subalterno, desde una mirada que fetichiza la modernidad y que se autoilusiona con un inminente ingreso al ámbito del desarrollo, a pesar de que la mitad de los peruanos se sienten excluidos y de que casi 500 años después, nuestros principales productos de exportación siguen siendo el oro y la plata. Este enfoque, como todos sabemos, fue popularizado con la famosa doctrina del "perro del hortelano". Al optar por exaltar a "Machu Picchu para el mundo", se reitera el viejo ideologema de la monumentalización de lo indígena como mera "ruina", como puro pasado, muy atractivo para el turista nacional o extranjero, pero que debe ser dejado atrás en aras del mito del progreso. Incas sí, indios no: ${ }^{17}$ admiremos el legado de las civilizaciones prehispánicas ya desaparecidas, invisibilicemos la cultura andina viva, cuyo símbolo paradigmático es justamente Arguedas.

Sin embargo, a pesar de que este año no haya estado dedicado oficialmente a su memoria, el 2011 quedará signado para la cultura peruana como el año de José María Arguedas.

\section{Referencias bibliográficas}

ARGUEDAS, José María (1983). Obras completas. Compilación y notas de Sybilla Arredondo de Arguedas. Lima: Editorial Horizonte.

ARGUEDAS, José María et al. (1985) ¿He vivido en vano? Mesa Redonda sobre Todas las sangres. 23 de junio de 1965. Lima: Instituto de Estudios Peruanos.

CASTRO KLAREN, Sara (1973). El mundo mágico de José María Arguedas. Lima: Instituto de Estudios Peruanos.

CORNEJO POLAR, Antonio (1997). Los universos narrativos de José María Arguedas. Lima: Horizonte.

CORNEJO POLAR, Antonio (1978)."El indigenismo y las literaturas heterogéneas: su doble estatuto socio-cultural”. Revista de Crítica Literaria Latinoamericana, 7-8; pp. 7-21.

CORNEJO POLAR, Antonio (1980). Literatura y sociedad en el Perú: la novela indigenista. Lima: Lasontay.

CORNEJO POLAR, Antonio (1994).Escribir en el aire. Ensayo sobre la heterogeneidad sociocultural en las literaturas andinas. Lima: Horizonte.

Cornejo Polar, Antonio (1995).“Condición migrante e intertextualidad multicultural: el caso de Arguedas”. Revista de Crítica Literaria Latinoamericana 42; pp.101-109.

CORNEJO POLAR, Antonio (1996). "Una heterogeneidad no dialéctica: sujeto y discurso migrantes en el Perú moderno". Revista Iberoamericana 176-177; pp. 837-844.

16 Transculturación narrativa en América Latina, 71.

17 Recojo esta frase del título de un conocido estudio de Cecilia Méndez. 
ESCAJADILLO, Tomás (1970). "Meditación preliminar en torno a José María Arguedas y el indigenismo". Revista Peruana de Cultura 13-14; pp. 82-126.

ESCAJADILLO, Tomás (1994).La narrativa indigenista peruana. Lima: Amaru Editores.

ESCAJADILLO, Tomás (2004). "Ciro Alegría, José María Arguedas y el indigenismo de Mariátegui”. En Mariátegui y la literatura peruana. Lima: Amaru Editores; pp. 233-287.

ESCOBAR, Alberto (1971) [1965]. "La guerra silenciosa de Todas las sangres. Patio de Letras. Caracas: Monte Ávila editores; pp. 365-381.

ESCOBAR, Alberto (1984). Arguedas o la utopía de la lengua. Lima: Instituto de Estudios Peruanos.

ESPEZÚA, Dorian (2011). Todas las sangres en debate. Científicos sociales versus críticos literarios. Lima: Magreb.

ISER, Wolfgang (1987). El acto de leer. Teoría del efecto estético. Madrid, Taurus.

JAUSS, Hans Robert (1976). La literatura como provocación. Barcelona: Península.

JAUSS, Hans Robert (1986). Experiencia estética y hermenéutica literaria. Madrid: Taurus.

LIENHARD, Martin (1981). Cultura popular andina y forma novelesca. Zorros y danzantes en la última novela de Arguedas. Lima: Latinoamericana Editores - Tarea.

MAMANI, Mauro (2011). José María Arguedas. Urpi, fieru, qori, sonqoyki. Estudio sobre la poesía de Arguedas. Lima: Ediciones Copé - Petroperú.

MAYORAL, José Antonio (Ed.) (1987). Estética de la recepción. Madrid: Arco/Libros, 1987.

MÉNDEZ, Cecilia (2000). Incas sí, indios no: Apuntes para el estudio del nacionalismo criollo en el Perú. Lima: Instituto de Estudios Peruanos, Documentos de Trabajo $\mathrm{N}^{\circ} 56$.

ORTEGA, Julio (1982). Texto, comunicación y cultura. Los ríos profundos de José María Arguedas. Lima: CEDEP.

PINILLA, Carmen María (1994). Arguedas: conocimiento y vida. Lima: Fondo Editorial de la Pontificia Universidad Católica del Perú.

PORTUGAL, José Alberto (2007). Las novelas de José María Arguedas. Lima: Fondo Editorial de la Pontificia Universidad Católica del Perú.

QUIJANO, Aníbal (2003). "Colonialidad del poder, eurocentrismo y América Latina”. En Edgardo Lander (compilador) La colonialidad del saber: eurocentrismo y ciencias sociales. Perspectivas latinoamericanas, Buenos Aires: CLACSO-UNESCO, Unidad Regional de Ciencias Sociales y Humanas para América Latina y el Caribe; pp. 201-246.

RAMA, Ángel (1982). Transculturación narrativa en América Latina. México: Siglo XXI.

RICOEUR, Paul (1986). Du texte à l' action. Essais d' herméneutique II. París: Seuil.

ROWE, William (1979). Mito e ideología en la obra de José María Arguedas. Lima: Instituto Nacional de Cultura.

VARGAS LLOSA, Mario (1964). “José María Arguedas descubre al indio auténtico”. Visión del Perú 1; pp. 3-7.

VARGAS LLOSA, Mario (1969). "Novela primitiva y novela de creación en América Latina”. Revista de la Universidad de México, XXII, 10 ; 29-36.

VARGAS LLOSA, Mario (1996). La utopía arcaica. José María Arguedas y las ficciones del indigenismo. México: Fondo de Cultura Económica.

V.AA. (2011). Arguedas. Poética de la verdad. Segunda mesa redonda sobre Todas las sangres. Lima: Fondo Editorial de la Biblioteca Nacional del Perú.

WARNING, Rainer (Ed.) (1989). Estética de la recepción. Madrid: Visor. 